Ultimate structural and fatigue damage loads of a spar-type floating wind turbine

Liang Li ${ }^{\mathrm{a}}$, Zhi-Ming Yuan ${ }^{\mathrm{a}}$, Chunyan $\mathrm{Ji}^{\mathrm{b},{ }^{*}}$, Yan $\mathrm{Gao}^{\mathrm{a}}$

a Department of Naval Architecture, Ocean and Marine Engineering, University of Strathclyde, Glasgow, UK

${ }^{\mathrm{b}}$ School of Naval Architecture and Ocean Engineering, Jiangsu University of Science and Technology, Zhenjiang, China

jichunyanjkd@163.com 


\title{
Ultimate structural and fatigue damage loads of a spar-type floating wind turbine
}

\begin{abstract}
This study addresses the ultimate structural and fatigue damage loads of a spartype offshore floating wind turbine under joint excitations of wind and wave. Aerohydro-servo-elastic coupled analysis is performed in time-domain to capture the dynamic responses of the floating wind turbine. Based on the mean up-crossing rate method, the short-term ultimate structural load is estimated. The cumulative fatigue damage load is computed with the S-N method. It is shown that the lowlevel ultimate load is mostly influenced by wind forces whereas the high-level ultimate load is more closely related with wave forces. The wave excitations dominate the fatigue damage at tower top and tower base, whereas the mooring line fatigue damage is more sensitive to the wind forces.
\end{abstract}

Keywords: ultimate structural load; fatigue damage load; floating wind turbine; up-crossing rate; S-N method

Subject classification codes: include these here if the journal requires them

\section{Introduction}

With expanding global demand for power and increasing public awareness to sustainable development, great efforts are taken to exploit the offshore renewable energy resources and a set of offshore renewable energy devices are developed. Statoil launched a demo project of a spar-type offshore floating wind turbine, namely the Hywind concept, which is the first full scale floating wind turbine that has ever been built (Nielsen et al, 2006). Principle Power (2017) installed a full-scale 2MW WindFloat prototype near the coast of Portugal. At the same time, researchers across the world are working on the numerical and experimental studies of a floating wind turbine. Li et al. (2014) and Li et al. (2015) investigated the global motions of a semi-type offshore floating wind turbine. $\mathrm{Hu}$ et al. (2016a) studied the transient response of a floating wind turbine after an emergency shutdown. Li et al. (2018b) studied the power production and platform motions of a floating wind turbine incorporated with wave energy converter and tidal turbines. Duan 
et al. (2016) conducted a model test research on a spar-type floating wind turbine. Li et al. (2018a) came up with a free-rotation method to model the wind turbine thrust forces in the model test environment.

In practice, the ultimate structural and fatigue damage loads are essential items in the design of an offshore renewable energy device. Cheng et al. (2017) compared the extreme structural response and fatigue damage of a horizontal axis floating wind turbine and a vertical axis floating wind turbine. $\mathrm{Hu}$ et al. (2016b) developed an integrated structural strength analysis method for a spar-type floating wind turbine. Inertia and wave-induced loads were addressed with a quasi-static method and the wind force was dealt with a static approach. Li et al. (2016) discussed the limitation of the original environmental contour method in the application to offshore wind turbines. A modified approach was proposed and they showed that the predicted results were of higher accuracy. Michailides et al. (2016) examined the response of a combined wind/wave energy concept in extreme environmental conditions with both experimental and numerical methods. Liu et al. (2017) studied the aerodynamic damping effect on offshore wind turbine tower fatigue loads and different aerodynamic damping models were used. Aggarwal et al. (2017) studied the nonlinear short-term extreme responses of a spar-type floating wind turbine. Li et al. (2017) investigated the fatigue analysis for the tower base of a spar-type wind turbine. The effects of simulation length, wind-wave misalignment on the fatigue damage were studied. Marino et al. (2017) investigated the fatigue loads of a floating wind turbine with both linear and nonlinear wave models. Graf et al. (2016) used the Monte Carlo approach to evaluate the long-term fatigue loads of a floating wind turbine. They found that this approach significantly increased the computational efficiency, but the effectiveness was reduced as the nonlinearity effect became important. 
This study examines the ultimate structural load as well as fatigue damage load of a spar-type offshore floating wind turbine in a wide range of environmental conditions. The mean-up crossing rate method is used to evaluate the extreme response and the fatigue damage load is estimated with the S-N approach. It will investigate how the wind and waves influence the extreme responses and fatigue damage of the floating wind turbine.

\section{Model description}

A spar-type offshore floating wind turbine, namely the OC3-Hywind concept (Jonkman, 2010), is considered in this study. The main dimensions of the spar platform are presented in Table 1 and the inertial properties are listed in Table 2. The NREL 5WM baseline wind turbine (Jonkman et al., 2009) is mounted on the spar platform.

Table 1. Main dimensions of the Hywind.

\begin{tabular}{ll}
\hline Item & Value \\
\hline Draft & $120 \mathrm{~m}$ \\
Tower base above still water level (SWL) & $10 \mathrm{~m}$ \\
Depth to top of taper below SWL & $4 \mathrm{~m}$ \\
Depth to bottom of taper below SWL & $12 \mathrm{~m}$ \\
Platform diameter above taper & $6.5 \mathrm{~m}$ \\
Platform diameter below taper & $9.4 \mathrm{~m}$ \\
\hline
\end{tabular}

Table 2. Inertial properties of the Hywind.

\begin{tabular}{ll}
\hline Item & Value \\
\hline Platform mass & $7.47 \times 10^{6} \mathrm{~kg}$ \\
Centre of mass (CM) below SWL & $89.9 \mathrm{~m}$ \\
Roll inertia about CM & $4.23 \times 10^{9} \mathrm{~kg} \cdot \mathrm{m}^{2}$ \\
Pitch inertia about CM & $4.23 \times 10^{9} \mathrm{~kg} \cdot \mathrm{m}^{2}$ \\
Yaw inertia about CM & $1.64 \times 10^{8} \mathrm{~kg} \cdot \mathrm{m}^{2}$ \\
\hline
\end{tabular}

The Hywind is operated at sea site with a water depth of $320 \mathrm{~m}$ and moored by three slack catenary lines. The fairleads are connected to the platform at $70 \mathrm{~m}$ below the still water level. Figure 1 displays the configuration of the mooring system. Three lines are oriented at $60^{\circ}, 180^{\circ}$, and $300^{\circ}$ about the vertical axis. The relevant properties of the mooring lines are listed in Table 3. 


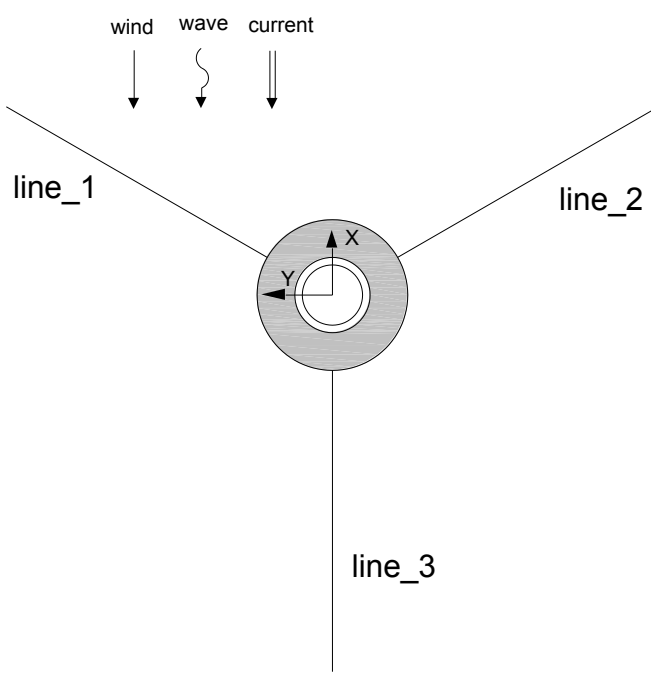

Figure 1. Configuration of mooring lines.

Table 3. Mooring line properties.

\begin{tabular}{ll}
\hline Item & Value \\
\hline Depth to anchors & $320 \mathrm{~m}$ \\
Depth of fairleads & $70 \mathrm{~m}$ \\
Radius to anchors & $853.87 \mathrm{~m}$ \\
Radius to fairleads & $5.2 \mathrm{~m}$ \\
Unstretched mooring line length & $902.2 \mathrm{~m}$ \\
Mooring line diameter & $0.09 \mathrm{~m}$ \\
Equivalent mooring line mass density & $77.71 \mathrm{~kg} / \mathrm{m}$ \\
Equivalent mooring line extensional stiffness & $384,243 \mathrm{kN}$ \\
\hline
\end{tabular}

\section{Analysis methodology}

\subsection{Time-domain coupled analysis}

The aero-hydro-servo-elastic simulation code FAST (Jonkman and Buhl Jr, 2005) is used to simulate the structural response of Hywind under the joint excitations of wind and wave. In FAST, the aerodynamic loads are calculated based on the blade element momentum method with the consideration of rotor-wake effects and dynamic stall. The hydrodynamic models simulate the incident waves and solve for the hydrostatic, radiation, diffraction, and viscous loads on the offshore substructure, using potential flow theory. The control and electrical system models simulate the controller logic, sensors, and actuators of the blade-pitch, generator-torque, nacelle-yaw, and other control devices, 
as well as the generator and power-converter components of the electrical drive. Couplings between all models are achieved through a modular interface and coupler. Please refer to (Jonkman and Buhl Jr, 2005) for the details of fundamental theory applied and the numerical modeling.

\subsection{Ultimate load}

The mean up-crossing rate, which represents the average frequency of the positive slop crossings of a defined level, is used to estimate the ultimate structural loads. The random number of up-crossing over a certain period can be approximated by the Poisson distribution. Therefore, the distribution of extreme value $y_{\max }$ of a random process $y(t)$ is described by

$$
P\left(y_{\max } \leq y_{0}\right)=\exp \left(-\int_{0}^{T} v^{+}\left(y_{0}, t\right) d t\right)
$$

where $v^{+}\left(y_{0}, t\right)$ is the up-crossing rate corresponding to level $y_{0}$. The probability of $y_{\max }$ exceeding a defined level $y_{0}$ is given by

$$
\begin{aligned}
& P\left(y_{\max }>y_{0}\right)=1-\exp \left(-\bar{v}^{+}\left(y_{0}\right) T\right) \\
& \bar{v}^{+}\left(y_{0}\right)=\frac{1}{T} \int_{0}^{T} v^{+}\left(y_{0}, t\right) d t
\end{aligned}
$$

If the defined level $y_{0}$ is low, then just a few simulation realizations of the random process will produce satisfactory approximation. Nevertheless, extensive simulations are required to evaluate the extreme values in the tail region. To save computation resources, the extrapolation method proposed by Naess and Gaidai (2008) is used here to predict the mean up-crossing rate corresponding to high level $y_{0}$.

The extrapolation method is based on the observation of marine structures so that it is applicable to the Hywind. The mean up-crossing rate is approximated by 


$$
\begin{aligned}
& \bar{v}^{+}\left(y_{0}\right) \approx v_{f i t}^{+}\left(y_{0}\right) \\
& v_{f i t}^{+}\left(y_{0}\right)=q \cdot \exp \left\{-a\left(y_{0}-b\right)^{c}\right\}
\end{aligned}
$$

where $q, a, b$ and $c$ are all constant values. In the work of Naess and Gaidai (2008), the first procedure is to determine the value of $q$. Afterward, it is easy to find that plotting $\log \left|\log \left(v_{f i t}^{+} / q\right)\right|$ versus $\log (y-b)$ exhibits a linear tail behaviour. Figure 2 shows the extrapolation of mean up-crossing rate, which can approximate the mean up-crossing well at low defined level $y_{0}$. Nevertheless, $\bar{v}^{+}$becomes unstable in the tail region as the sample size is sufficient to produce reliable results. Therefore, the fitted up-crossing rate $v_{f i t}^{+}$is used in the following part of this paper to represent the extreme response in the tail region.

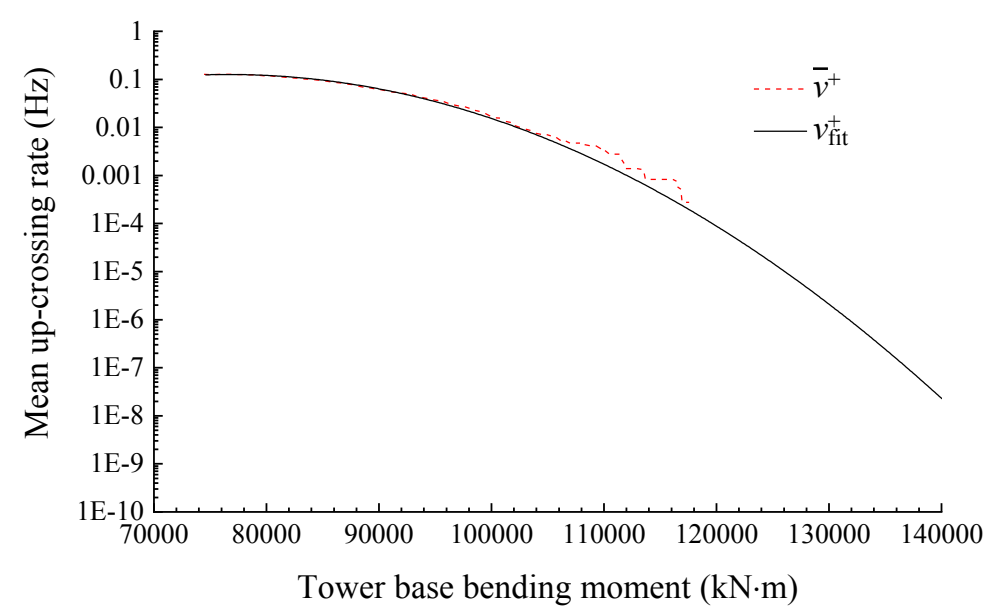

Figure 2. Extrapolation of mean up-crossing rate of the tower base bending moment, Case2.

\subsection{Fatigue damage load}

Wind, wave and inertial loads applied at structural connections will cause fluctuation, which produces fatigue damage. The $\mathrm{S}-\mathrm{N}$ method is used to evaluate the corresponding fatigue damage loads. The fluctuating loads are broken down into individual hysteresis cycles by matching local minima with local maxima in the time series, which are characterized by a load-mean and range. The cycles are counted by the rain-flow counting algorithm. It is assumed that the damage accumulates linearly with each of these cycles 
according to Miner's Rule. In this case, the overall equivalent damage load $(D L)$ produced by all the cycles is given by

$$
D L=\left[\frac{\sum\left(n_{i}\left(L_{i}\right)^{m}\right)}{n^{\text {STeq }}}\right]^{\frac{1}{m}}
$$

where $n^{S T e q}=f_{e q} \cdot T$ is the total equivalent fatigue counts, $f_{e q}(1 \mathrm{~Hz}$ in this paper $)$ is the fatigue load frequency and $T$ is the simulation time. $n_{i}$ is the cycle count and $L_{i}$ is the cycle's load range about a fixed load-mean. $m$ is the Whöler exponent. A value of $m=4$ is used in this study.

It is worth noting that the Miner's Rule neglects the load sequence effect, the initial defect, final crack state, etc., which have influences on the fatigue damage. To fully explain the fatigue phenomena, the crack propagation theory should be used (Cui, 2002). For example, Cui et al. (2011) proposed a unified fatigue prediction method basedo $\mathrm{n}$ the crack propagation theory for marine structures. Therefore, the fatigue analysis in this work is a preliminary assessment.

\section{Environmental conditions and load cases}

In a realistic sea site, the wind and the waves are always correlated. The joint probabilistic model of mean wind speed $U_{\mathrm{w}}(10 \mathrm{~m}$ above the mean sea level $)$, significant wave height $H_{\mathrm{s}}$ and peak period $T_{\mathrm{p}}$ that proposed by Johannessen et al. (2001) is used here. Firstly, the mean wind speed $U_{\mathrm{w}}$ is chosen. Subsequently, the fitting curve provided is used to acquire the mean significant wave height corresponding to a given mean wind speed. Finally, the mean peak period at given $U_{\mathrm{w}}$ and $H_{\mathrm{s}}$ is determined according to Eq. (5). The environmental condition considered in this study are listed in Table 4.

$$
T_{p}=\left(4.883+2.68 \cdot H_{s}^{0.529}\right) \cdot\left[1-0.19 \cdot\left(\frac{U_{w}-\left(1.764+3.426 \cdot H_{s}^{0.78}\right)}{1.764+3.426 \cdot H_{s}^{0.78}}\right)\right]
$$


Table 4. Environmental conditions.

\begin{tabular}{ccccc}
\hline & $U_{\mathrm{w}}(\mathrm{m} / \mathrm{s})$ & $U_{\text {hub height }}(\mathrm{m} / \mathrm{s})$ & $H_{s}(\mathrm{~m})$ & $T_{p}(\mathrm{~s})$ \\
\hline Case1 & 5 & 6.8 & 2.38 & 9.84 \\
Case2 & 8 & 10.8 & 3.13 & 10.17 \\
Case3 & 10 & 13.6 & 3.55 & 10.29 \\
Case4 & 12 & 16.3 & 4.17 & 10.62 \\
Caes5 & 14 & 19.0 & 4.75 & 10.89 \\
\hline
\end{tabular}

A realistic wind field always varies with height. A power law is used to estimate the wind profile $U(z)$ at the height of $z$ above the mean sea level (see Figure 3)

$$
U(z)=U_{w}\left(\frac{z}{10}\right)^{\alpha}
$$

$\alpha$ is the power law exponent which is selected to be 0.14 according to IEC $614000-3$ (IEC, 2009). Figure 4 plots the variation of steady wind turbine thrust force with wind speed. As shown, the wind turbine thrust force is largest in Case2.

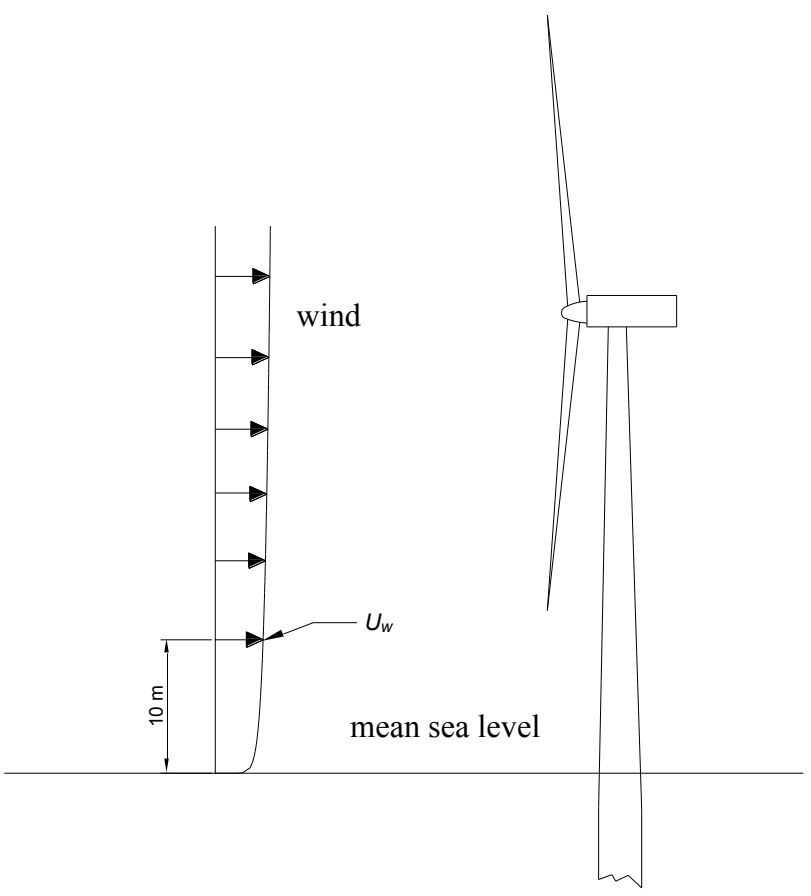

Figure 3. Wind profile. 


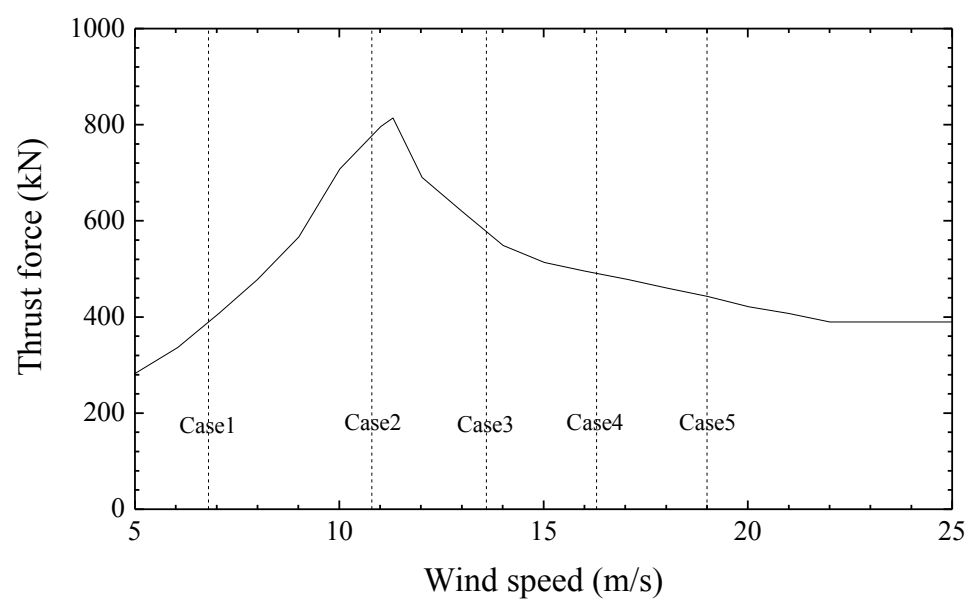

Figure 4. Steady wind turbine thrust force.

\section{Simulation results}

1-hr short-term ultimate structural and fatigue damage loads are investigated in this section. The total simulation length is set to $4000 \mathrm{~s}$ and only data of the last $3600 \mathrm{~s}$ will be collected to get rid of the transient effects arising in the initial simulation stage. Structural loads at four critical connections are considered in this paper (see Table 5).

Table 5. Structural responses considered.

\begin{tabular}{ll}
\hline Term & Symbol \\
\hline Tower top fore-aft shear force & YawBrFx \\
Tower base fore-aft bending moment & TwrBsMy \\
Tower base fore-aft vertical force & TwrBsFz \\
Mooring line tension force at anchor (line 2) & $\mathrm{T}_{2}$ \\
\hline
\end{tabular}

\subsection{Dynamic structural response}

Firstly, we examine the dynamic structural responses, which are the basis of the evaluation of ultimate and fatigue damage loads. Figure 5 plots the tower base bending moment histories in Case2. Due to the wind turbine thrust force, the mean value is nonzero. It implies that the ultimate structural load is more likely to exceed a certain level when subject to large wind force. Besides, the obvious fluctuating component is observed. Therefore, the ultimate structural load is determined by both aerodynamic and hydrodynamic excitations. Figure 6 shows the power spectrum density of the tower base 
bending moment. The response energy is mainly located within the wave frequency, indicating that the fluctuation is induced by hydrodynamic excitations. Since the fatigue caused by response fluctuation so that wave forces play an important role in the fatigue damage load. Figure 7 summarises the statistics of structural loads. Except for the tower base vertical force, the mean values of the other three structural responses are all proportional to the wind turbine thrust force. Since the wind mainly induces loads along surge and pitch mode, the tower base vertical force is hardly influenced by the wind speed. The sea state seems to have a very limited influence on the tower base vertical force and mooring line tension since the standard deviations are very small. On the contrary, the tower top shear force and tower base bending moment are amplified as the sea state becomes severe.

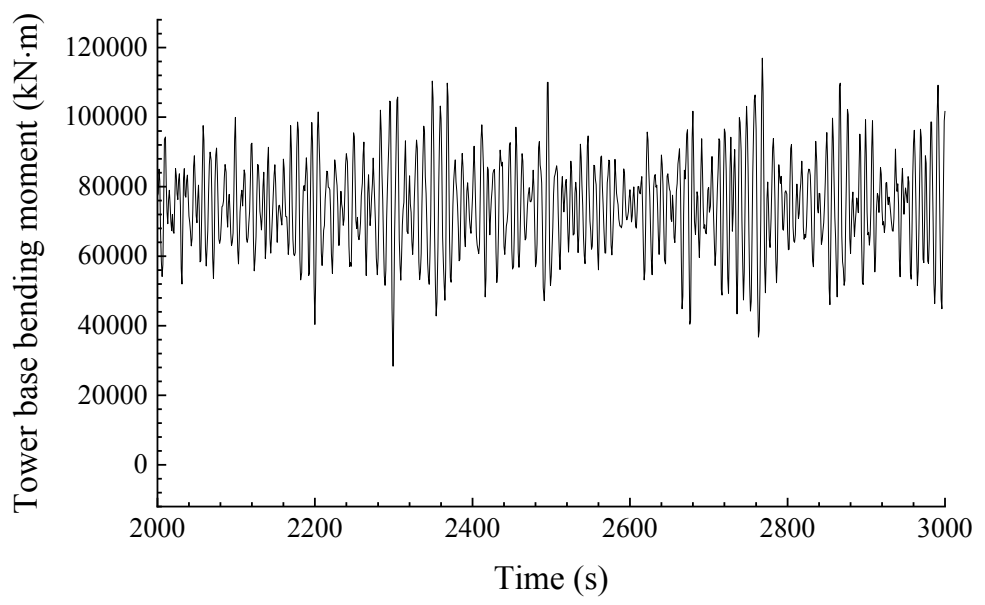

Figure 5. Time-series of tower base fore-aft bending moment, Case2. 


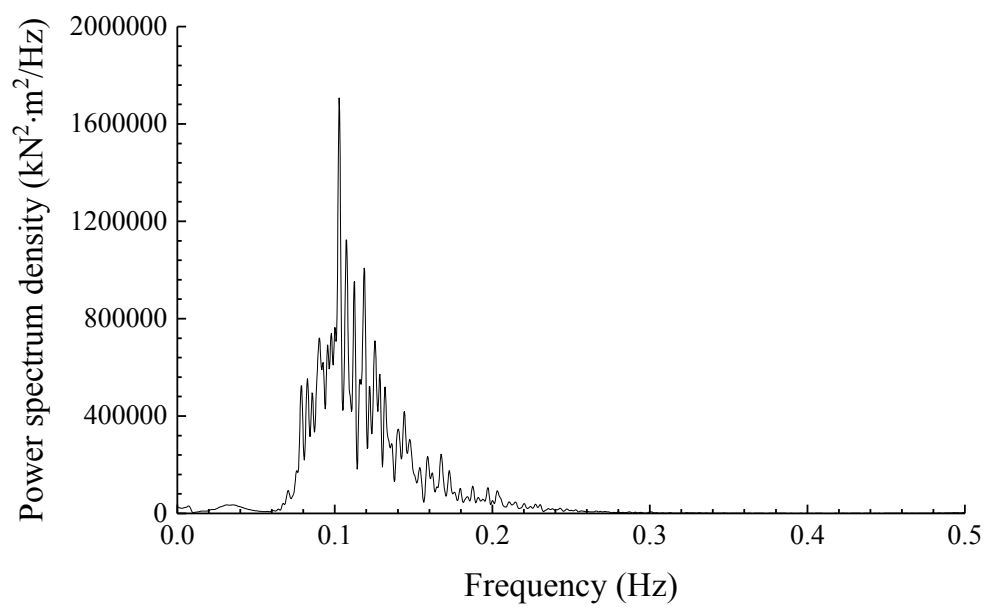

Figure 6. Power spectrum density of tower base fore-aft bending moment, Case2.
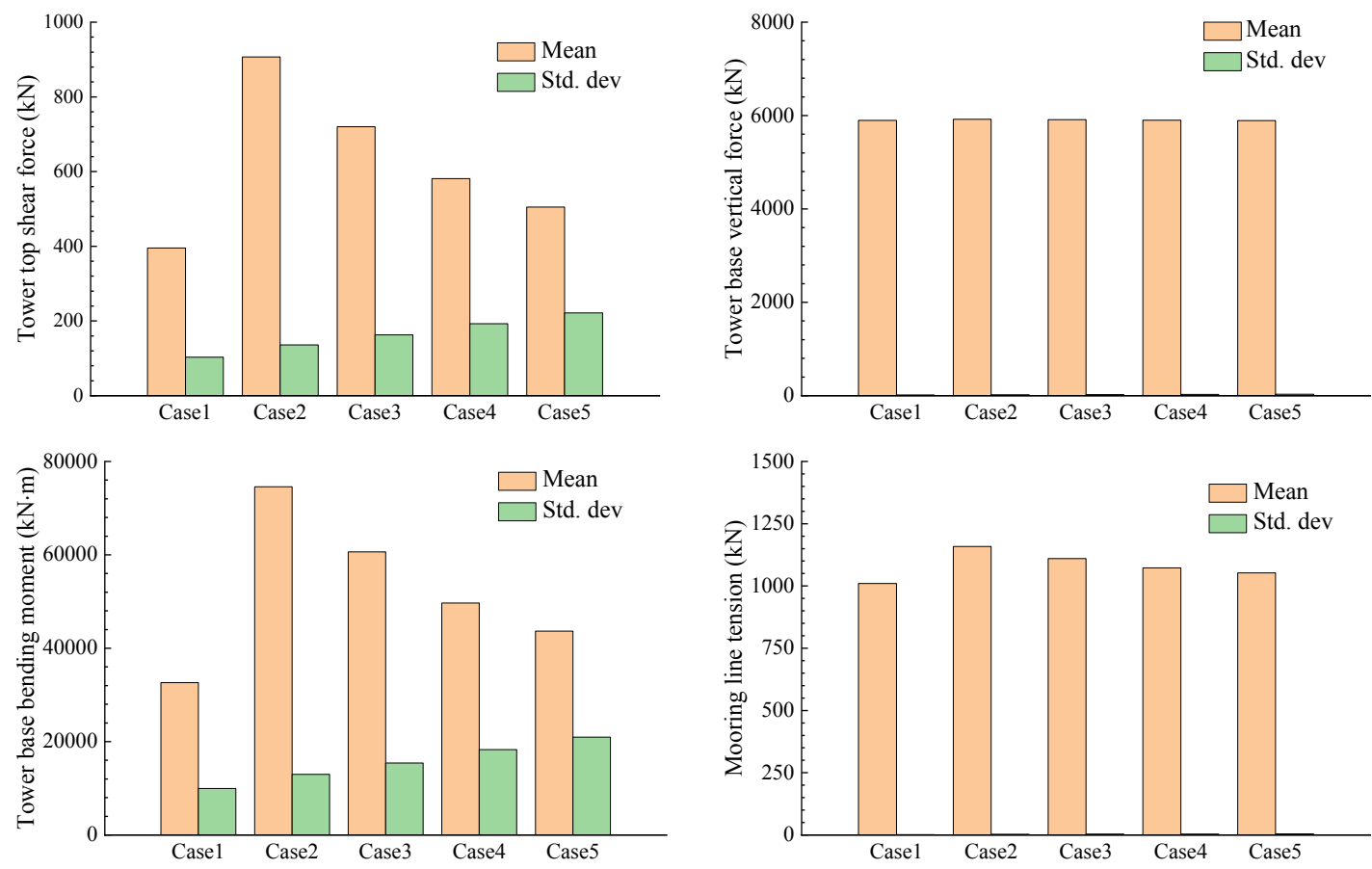

Figure 7. Statistics of dynamic structural responses.

\subsection{Ultimate structural load}

Figure 8 shows the extrapolated mean up-crossing rate of the fore-aft tower top shear force. Within low-level up-crossing rate range, the ultimate shear force is mainly governed by the wind turbine thrust force. For example, the ultimate shear force is largest in Case 2. This is because the low-level up-crossing rate is more closely related to mean value of the response. Within high-level range, the wave forces become important and the ultimate load in severe sea state is larger. 


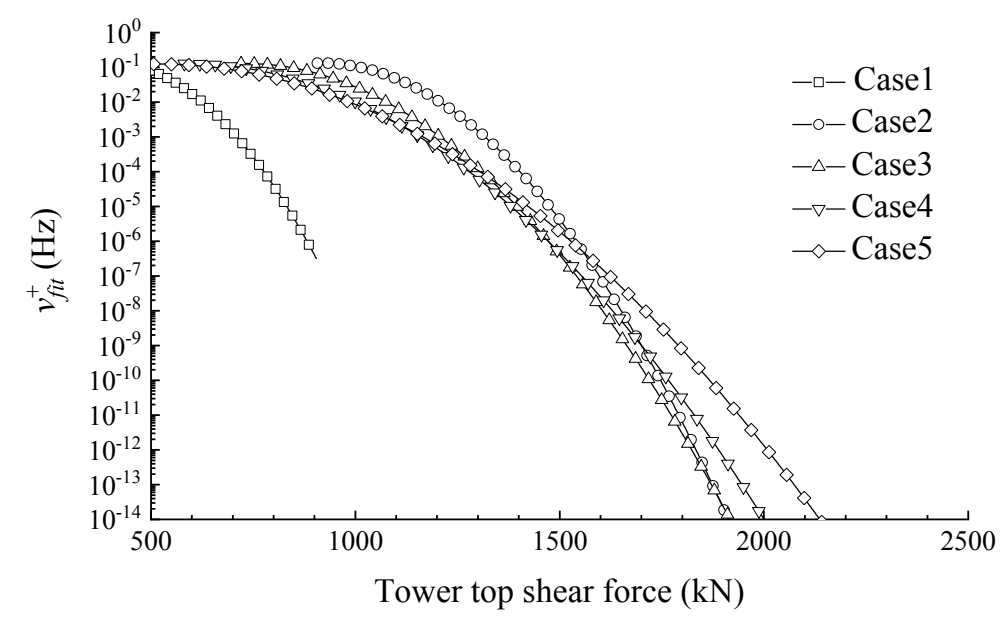

Figure 8. Extrapolated up-crossing rate of tower top shear force.

The up-crossing rates of ultimate fore-aft tower base bending moment are plotted in Figure 9, where similar variation trend is observed. The ultimate bending moment is dominated by both the wind forces and the wave forces, and the aerodynamic effect tends to be more significant within low up-crossing rate range. Nevertheless, the ultimate tower base vertical load varies little with the environmental conditions (see Figure 10). Regardless of the variations of wind speed and sea waves, the ultimate vertical forces in the five simulation cases differ than less $2 \%$. As discussed before, the wind turbine thrust force induces very little vertical load at the tower base so that wind speed has a limited influence on the ultimate load. Besides, the spar platform is subject to very small vertical wave excitation due to its geometry shape. Consequently, the platform heave motion increases very slightly even if the sea state becomes severe. Actually, the ultimate tower base vertical load is nearly constant and equal to the mass of the wind turbine (587460 $\mathrm{kg})$. 


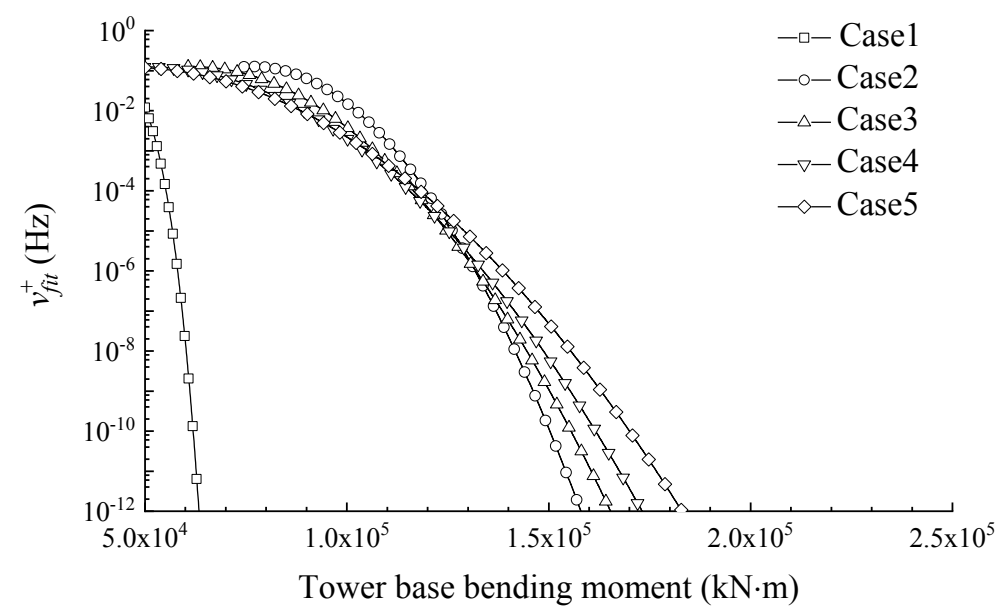

Figure 9. Extrapolated up-crossing rate of tower base bending moment.

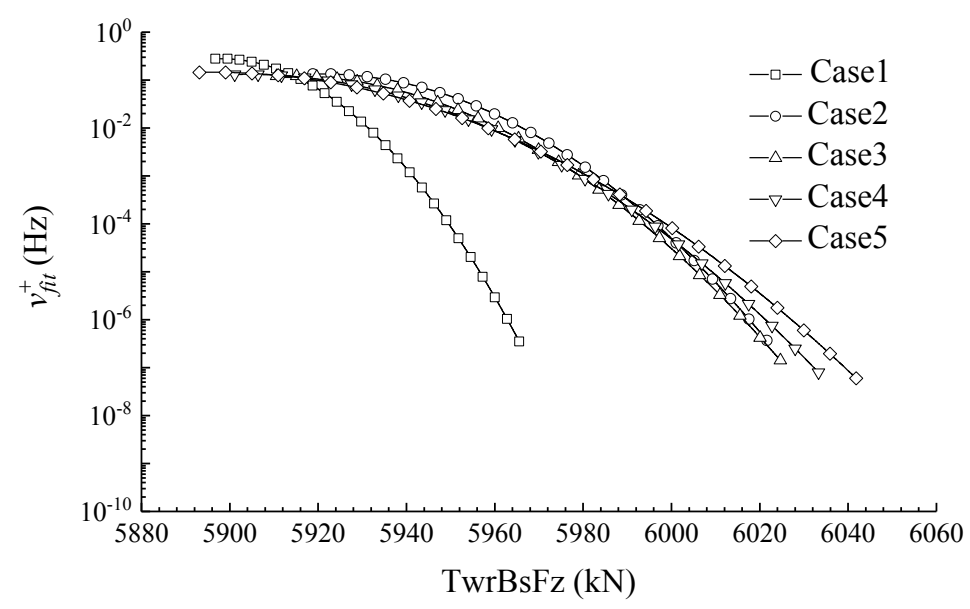

Figure 10. Extrapolated up-crossing rate of tower base vertical force.

Unlike the structural loads at tower top and tower base, the ultimate mooring line tension seems to be governed by the wind force alone. The ultimate mooring tension in Case 5 is the second lowest even if the sea state is the most severe. Due to the wind turbine thrust force, the platform is pushed away from the initial position and thereby the mooring line bear more loads to sustain the platform. Although the wave excitation also induces some mooring tension forces, this fluctuating component is negligible. Consequently, the wind force dominates the ultimate mooring line tension force. 


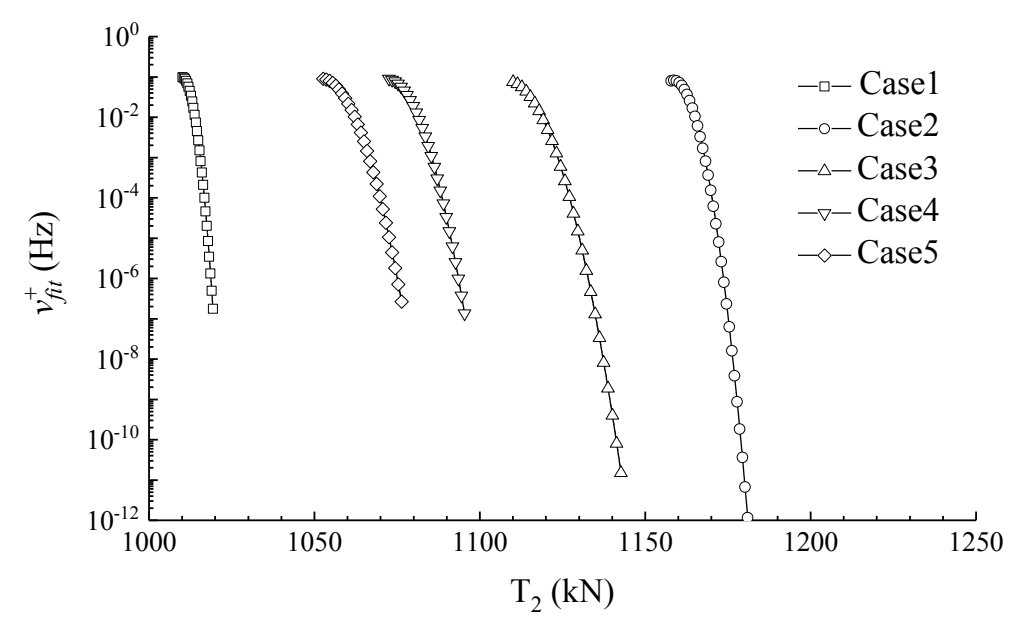

Figure 11. Extrapolated up-crossing rate of fairlead tension force (fairlead 2)

\subsection{Fatigue damage load}

Figure 12 displays the equivalent fatigue damage loads at the connections concerned. The fatigue damage loads at the tower top and tower base all increase as the sea state becomes severe. It indicates that the rated operational state is not the critical condition even if the wind turbine thrust force reaches its maximum design value. However, the mooring fatigue load is determined by the wind force rather than the wave force. It is because the mooring line force is nearly induced by the wind force alone.

As shown, the mooring line fatigue load and vertical tower base fatigue load are relatively small, implying that the fatigue is not a crucial issue at the two connections. Nevertheless, the tower base bending moment fatigue load reaches as high as $35000 \mathrm{kN} \cdot \mathrm{m}$ in Case5. This should be attributed to the large weight of wind turbine and its high center of gravity, which produce large bending moment even under small pitch motion. Consequently, more attention should be paid to the fatigue bending moment at the tower base in the design of an offshore floating wind turbine. 

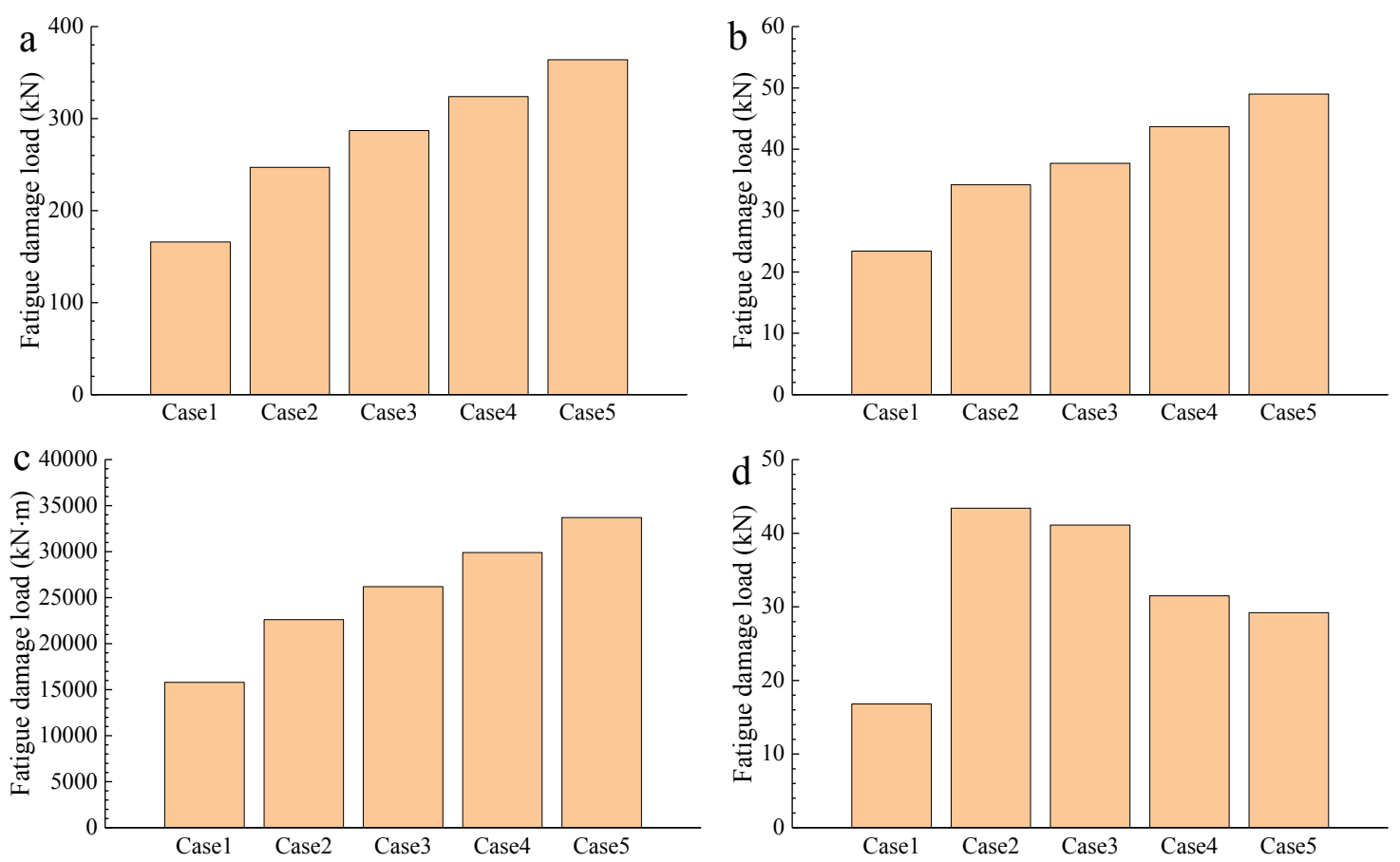

Figure 12. Fatigue damage loads, (a) tower top shear force; (b) tower base vertical force; (c) tower base bending moment; (d) Mooring line tension.

\section{Conclusions}

The short-term ultimate structural and fatigue damage loads of a floating wind turbine are addressed in this study. The mean up-crossing method is used to predict the extreme values of the stochastic responses. The size of simulation realizations is reduced by an extrapolation method, which approximates the up-crossing rate in the tail region. The cumulative fatigue damage is calculated based on the S-N method.

For tower top shear force and tower base bending moment, the ultimate load is dominated by wind force within low-level up-crossing rate range whereas the wave excitation plays a more important role within high-level range. The ultimate tower base vertical force hardly varies with the environmental condition. In regarding of the mooring line concerned, the ultimate load is totally determined by wind turbine thrust force.

Except for the mooring line, the tower top and tower base have a higher probability to fail under severe sea state. According to simulation results, the fatigue damage loads 
of tower base vertical force and mooring line tension are very limited. Nevertheless, the tower base is a critical connection since the fatigue bending moment load is very high.

\section{Acknowledgment}

The authors would like to acknowledge China Scholarship Council for the financial support (No. 201506230127).

\section{References}

Aggarwal, N., Manikandan, R., Saha, N., 2017. Nonlinear short term extreme response of spar type floating offshore wind turbines. Ocean Engineering 130, 199-209.

Cheng, Z.S., Madsen, H.A., Chai, W., Gao, Z., Moan, T., 2017. A comparison of extreme structural responses and fatigue damage of semi-submersible type floating horizontal and vertical axis wind turbines. Renewable Energy 108, 207-219.

Cui, W.C., 2002. A state-of-the-art review on fatigue life prediction methods for metal structures. Journal of Marine Science and Technology 7 (1), 43-56

Cui, W.C., Wang, F., Huang, X.P., 2011. A unified fatigue life prediction method for marine structures. Marine Structures 24 (2), 153-181.

Duan, F., Hu, Z.Q., Niedzwecki, J.M., 2016. Model test investigation of a spar floating wind turbine. Marine Structures 49, 76-96.

Graf, P.A., Stewart, G., Lackner, M., Dykes, K., Veers, P., 2016. High-throughput computation and the applicability of Monte Carlo integration in fatigue load estimation of floating offshore wind turbines. Wind Energy 19 (5), 861-872.

Hu, Z.Q., Li, L., Wang, J., Hu, Q.H., Shen, M.C., 2016a. Dynamic responses of a semitype offshore floating wind turbine during normal state and emergency shutdown. China Ocean Engineering 30 (1), 97-112.

Hu, Z.Q., Liu, Y., Wang, J., 2016b. An integrated structural strength analysis method for Spar type floating wind turbine. China Ocean Engineering 30 (2), 217-230.

IEC, 2009. International Standard 61400-3, Wind Turbines, Part 3: Design Requirements for Offshore Wind Turbines,.

Johannessen, K., Meling, T.S., Hayer, S., 2001. Joint distribution for wind and waves in the northern north sea, The Eleventh International Offshore and Polar Engineering Conference. International Society of Offshore and Polar Engineers.

Jonkman, J.M., 2010. Definition of the Floating System for Phase IV of OC3. Citeseer.

Jonkman, J.M., Buhl Jr, M.L., 2005. FAST User's Guide. National Renewable Energy Laboratory (NREL).

Jonkman, J.M., Butterfield, S., Musial, W., Scott, G., 2009. Definition of a 5-MW reference wind turbine for offshore system development. National Renewable Energy Laboratory Golden, CO.

Li, H.R., Hu, Z.Q., Wang, J., Meng, X.Y., 2017. Short-term fatigue analysis for tower base of a spar-type wind turbine under stochastic wind-wave loads. International Journal of Naval Architecture and Ocean Engineering 10 (1), 9-20.

Li, L., Gao, Y., Hu, Z., Yuan, Z., Day, S., Li, H., 2018a. Model test research of a semisubmersible floating wind turbine with an improved deficient thrust force correction approach. Renewable Energy 119, 95-105. 
Li, L., Gao, Y., Yuan, Z.M., Day, S., Hu, Z.Q., 2018b. Dynamic response and power production of a floating integrated wind, wave and tidal energy system. Renewable Energy 116, 412-422.

Li, L., Hu, Z., Wang, J., Hu, Q., 2014. Dynamic Responses of a Semi-type Offshore Floating Wind Turbine, ASME 2014 33rd International Conference on Ocean, Offshore and Arctic Engineering. American Society of Mechanical Engineers.

Li, L., Hu, Z.Q., Wang, J., Ma, Y., 2015. Development and Validation of an Aero-hydro Simulation Code for Offshore Floating Wind Turbine. Journal of Ocean and Wind Energy 2 (1), 1-11.

Li, Q.Y., Gao, Z., Moan, T., 2016. Modified environmental contour method for predicting long-term extreme responses of bottom-fixed offshore wind turbines. Marine Structures 48, 15-32.

Liu, X., Lu, C., Li, G.Q., Godbole, A., Chen, Y., 2017. Effects of aerodynamic damping on the tower load of offshore horizontal axis wind turbines. Applied Energy 204, 11011114.

Marino, E., Giusti, A., Manuel, L., 2017. Offshore wind turbine fatigue loads: The influence of alternative wave modeling for different turbulent and mean winds. Renewable Energy 102, 157-169.

Michailides, C., Gao, Z., Moan, T., 2016. Experimental and numerical study of the response of the offshore combined wind/wave energy concept SFC in extreme environmental conditions. Marine Structures 50, 35-54.

Naess, A., Gaidai, O., 2008. Monte Carlo methods for estimating the extreme response of dynamical systems. Journal of Engineering Mechanics-Asce 134 (8), 628-636.

Nielsen, F.G., Hanson, T.D., Skaare, B., 2006. Integrated dynamic analysis of floating offshore wind turbines, 25th International Conference on Offshore Mechanics and Arctic Engineering. American Society of Mechanical Engineers, pp. 671-679.

Principle Power, 2017. http://www.principlepowerinc.com/. 
Table 1. Main dimensions of the Hywind.

Table 2. Inertial properties of the Hywind.

Table 3. Mooring line properties.

Table 4. Environmental conditions.

Table 5. Structural responses considered.

Figure 1. Configuration of mooring lines.

Figure 2. Extrapolation of mean up-crossing rate of the tower base bending moment, Case2.

Figure 3. Wind profile.

Figure 4. Steady wind turbine thrust force.

Figure 5. Time-series of tower base fore-aft bending moment, Case2.

Figure 6. Power spectrum density of tower base fore-aft bending moment, Case2.

Figure 7. Statistics of dynamic structural responses.

Figure 8. Extrapolated up-crossing rate of tower top shear force.

Figure 9. Extrapolated up-crossing rate of tower base bending moment.

Figure 10. Extrapolated up-crossing rate of tower base vertical force.

Figure 11. Extrapolated up-crossing rate of fairlead tension force (fairlead 2)

Figure 12. Fatigue damage loads, (a) tower top shear force; (b) tower base vertical force;

(c) tower base bending moment; (d) Mooring line tension. 